\title{
Sebaran Tingkat Kapasitas Wilayah Pesisir Bagian Barat Kabupaten Buleleng Terhadap Ancaman Peningkatan Muka Air Laut
}

\section{Wayan Krisna Eka Putra}

Masuk: 04092018 / Diterima: 28102018 / Dipublikasi: 31122018

(c) 2018 Fakultas Hukum dan IImu Sosial UNDIKSHA dan IGI

\begin{abstract}
This study aims to describe the distribution of the capacity level the coastal area of west Buleleng Regency from the threat of sea level rise and to know the ratio of the capacity level. The subjects in this study are village officials and staff BPBD Buleleng Regency, while the object of the research is level of capacity. The phenomenon described in this research is distribution of capacity level of coastal area in west Buleleng Regency. Stages conducted in this study consisted of data collection, weighting, determining the level of capacity until finally mapping the level of capacity. data analysis technique that used is qualitative descriptive analysis combined with spatial comparative analysis based on Geographic Information System (GIS) which is aimed to analyze comparison of capacity level among villages in coastal area. The results show that the distribution of the capacity of all coastal areas in west Buleleng Regency is the medium category. Assessments of capacity level indicate a lack of capacity indicators for several villages, particularly on the availability of threat maps and early warning systems. Therefore it is necessary to socialize the document of disaster study which has been made by BPBD of Buleleng Regency..
\end{abstract}

Keywords: Capacity Level; Costal Area; Sea Level

Abstrak Penelitian ini bertujuan mendeskripsikan sebaran tingkat kapasitas wilayah pesisir bagian barat Kabupaten Buleleng terhadap ancaman peningkatan muka air laut serta mengetahui perbandingan tingkat kapasitasnya. Subyek dalam penelitian ini adalah aparat desa dan staff BPBD Kabupaten Buleleng, sementara obyek penelitiannya adalah tingkat kapasitas. Fenomena yang dideskripsikan dalam penelitian ini terkait dengan sebaran tingkat kapasitas wilayah pesisir bagian barat Kabupaten Buleleng. Tahapan yang dilakukan dalam penelitian ini terdiri dari kegiatan pengumpulan data, pembobotan, penentuan tingkat kapasitas sampai akhirnya pemetaan tingkat kapasitas. Teknik analisis data yang digunakan adalah analisis deskriptif kualitatif dipadukan dengan analisis komparatif keruangan berbasis Sistem Informasi Geografis (SIG) yang ditujukan untuk menganalisis perbandingan tingkat kapasitas antar desa di wilayah pesisir. Hasil yang diperoleh menunjukkan bahwa sebaran tingkat kapasitas seluruh wilayah pesisir bagian barat Kabupaten Buleleng berada pada kategori sedang. Penilaian tingkat kapasitas menunjukkan adanya ketimpangan indikator kapasitas beberapa desa terutama mengenai ketersediaan peta ancaman dan sistem peringatan dini. Dengan demikian perlu dilakukan sosialisasi terhadap dokumen kajian bencana yang sudah dibuat oleh BPBD Kabupaten Buleleng.

Kata kunci: Tingkat Kapasitas; Wilayah Pesisir; Muka Air Laut

\section{Pendahuluan}

Kabupaten Buleleng merupakan salah satu kabupaten di Provinsi Bali yang berpotensi mengalami ancaman peningkatan muka air laut. Menurut data dari BAPEDA Bali (2010) dalam Butaru (2011), garis pantai tererosi paling tinggi

I Wayan Krisna Eka Putra

Jurusan D3 Survei dan Pemetaan Fakultas Hukum dan IImu Sosial Universitas Pendidikan Ganesha

krisna.ekaputra@yahoo.com dari ancaman peningkatan muka air laut terjadi di wilayah pesisir Kabupaten Buleleng yang mencapai 54.830 meter atau sekitar $45 \%$ dari panjang garis pantai Kabupaten Buleleng. Hasil penelitian Putra (2013) menemukan bahwa wilayah pesisir bagian barat Kabupaten Buleleng terancam mengalami peningkatan ratarata muka air laut mencapai $5,1 \mathrm{~cm}$ per tahun. 
Upaya mitigasi bencana dari adanya peningkatan muka air laut dapat dilakukan melalui penyediaan peta risiko bencana (Peraturan Kepala BNPB No. 4 Tahun 2008). Peta risiko bencana dapat dihasilkan melalui data indeks kerentanan, indeks kapasitas wilayah terancam yang dipadukan dengan data ancaman. Sebagai upaya mitigasi melalui penyediaan peta risiko bencana, merupakan suatu keharusan guna melakukan analisis lebih awal mengenai kerentanan dan kapasitas wilayah terdampak. Kerentanan merupakan keadaan atau sifat/perilaku manusia atau masyarakat yang menyebabkan ketidakmampuan menghadapi bahaya atau ancaman. Kapasitas didefinisikan sebagai sumber daya, cara dan kekuatan yang dimiliki masyarakat yang memungkinkan untuk mempertahankan dan mempersiapkan diri, mencegah, menanggulangi, meredam serta dengan cepat memulihkan diri akibat bencana (BNPB, 2008).

\section{Berbagai hasil penelitian} sebelumnya yang mengkaji mengenai ancaman bencana wilayah pesisir secara singkat dapat diuraikan sebagai perbandingan, Sihombing, dkk., (2012) menemukan bahwa peningkatan muka air laut di perairan Kabupaten Tuban Jawa Timur sebesar 0,72 cm/tahun. Damayanti (2012) menemukan bahwa rata-rata peningkatan muka air laut di perairan Kabupaten Pati sebesar 10,46 cm. Wirasatriya, dkk., (2011) menemukan bahwa besarnya kenaikan rata-rata muka air laut di kawasan pesisir Semarang adalah $5,43 \mathrm{~cm} /$ tahun. Sementara dari hasil penelitian Nugraha, (2013) diperoleh peningkatan muka air laut di wilayah perairan Semarang mencapai 11,6 cm/tahun. Putra (2013) menemukan bahwa wilayah pesisir bagian barat Kabupaten Buleleng terancam mengalami peningkatan rata-rata muka air laut mencapai $5,1 \mathrm{~cm}$ per tahun.
Penelitian tersebut masih fokus pada pengkajian ancaman wilayah pesisir yang mendefinisikan sebaran daerah terdampak, sementara secara khusus untuk menilai tingkat kapasitas belum banyak diungkap, sehingga kajian dalam artikel ini difokuskan untuk memetakan sebaran tingkat kapasitas wilayah pesisir bagian barat Kabupaten Buleleng.

\section{Metode}

Penelitian ini dilakukan di wilayah pesisir barat Kabupaten Buleleng dengan melakukan pemetaan pada 2 kecamatan yang terdiri dari 21 desa yang berbatasan langsung dengan laut. Subyek dalam penelitian ini adalah aparat desa dan staff Badan Penanggulangan Bencana Daerah (BPBD) Kabupaten Buleleng, sementara obyek penelitiannya adalah kapasitas masing-masing desa yang berbatasan langsung dengan laut di wilayah penelitian.

Tahapan penelitian dilakukan melalui pengumpulan data, pembobotan, penentuan tingkat kapasitas, pemetaan kapasitas, analisis data dan penulisan laporan penelitian. Lebih jelasnya mengenai tahapan penelitian disajikan melalui Gambar 1. 


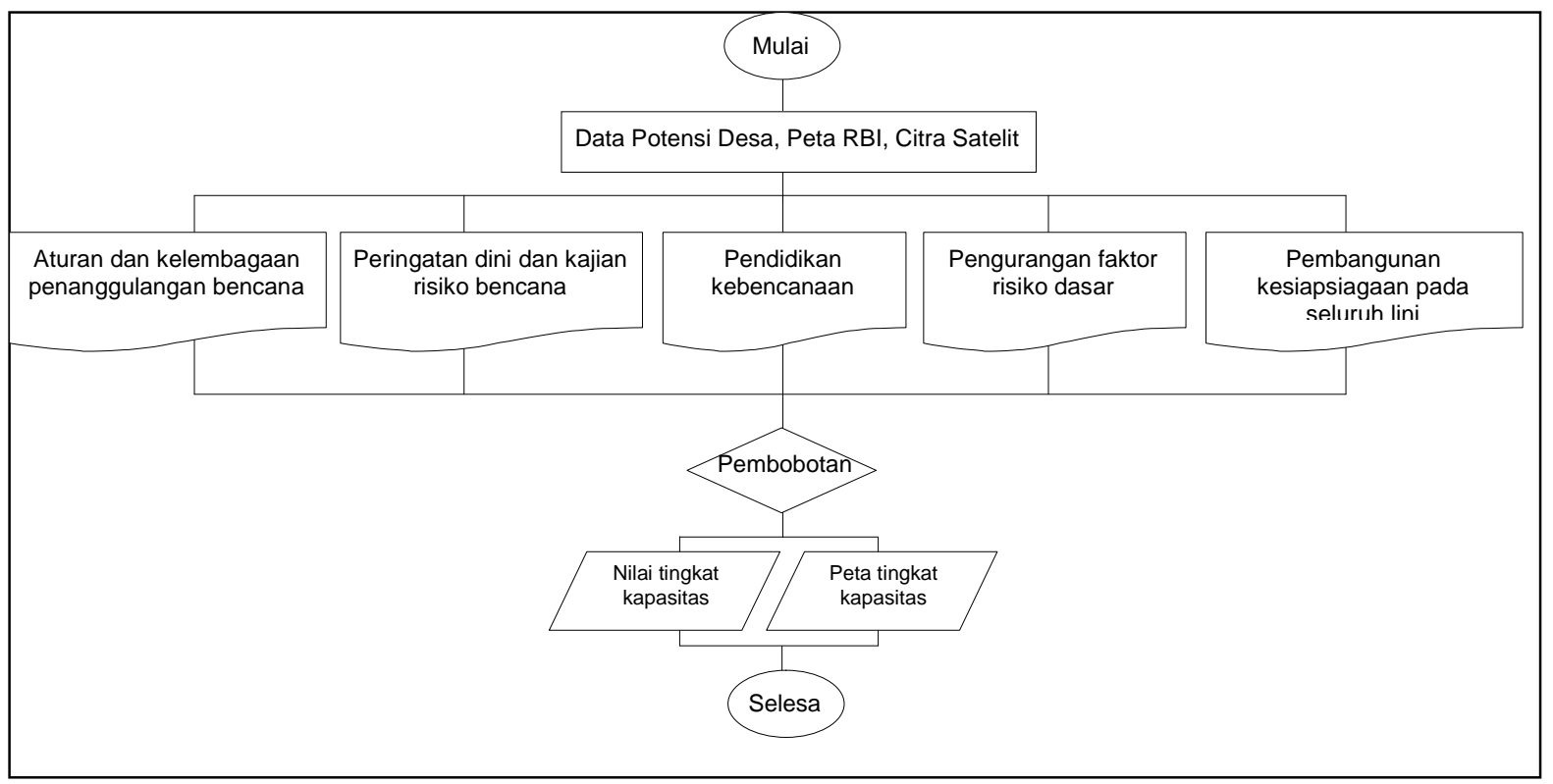

Gambar 1. Tahapan Penelitian

Merujuk pada Gambar 1, dapat dijelaskan bahwa data pemetaan tingkat kapasitas bersumber dari data potensi desa dan peta $\mathrm{RBI}$ yang dipadukan dengan hasil wawancara terhadap subyek penelitian. Data yang diperoleh dilakukan pembobotan sesuai dengan Peraturan Kepala BNPB No. 2 Tahun 2012. Pedoman pembobotan yang digunakan dalam penelitian ini berbasis pada pertanyaan yang akan diberikan pilihan jawaban antara "Ya" dan "Tidak", jika responden memberikan jawaban "Ya" maka akan memperoleh nilai "1", sebaliknya jika "Tidak" akan memperoleh nilai "0". Jika disandingkan dengan pertanyaan yang jumlahnya 88 , maka akan diperoleh nilai maksimal 88 dan nilai minimal 0. Dengan demikian untuk menetapkan tingkat kapasitas suatu wilayah dapat mengacu pada Gambar 2.

\begin{tabular}{|c|c|c|}
\hline \multicolumn{3}{|c|}{ Tingkat Kapasitas } \\
\hline Rendah & Sedang & Tinggi \\
\hline$<33$ & $33-66$ & $>66$ \\
\hline
\end{tabular}

\section{Gambar 2. Pedoman Penilaian Tingkat Kapasitas}

Selanjutnya hasil pembobotannya divisualisaikan menjadi peta tingkat kapasitas menggunakan software Sistem Informasi Geografis (SIG). Teknik analisis data yang digunakan dalam penelitian ini adalah analisis deskriptif kualitatif dipadukan dengan analisis komparasi keruangan yang menekankan pada perbandingan tingkat kapasitas wilayah yang satu dengan wilayah yang lain.

\section{Hasil dan Pembahasan}

Berdasarkan hasil pengumpulan data yang kemudian dilakukan pengolahan data, diperoleh total skor kapasitas wilayah bagian barat Kabupaten Buleleng berada pada rentangan 33-66. Informasi lebih rinci skor kapasitas wilayah dirinci per desa tersajikan pada Tabel 1. 
Tabel 1.Rekapitulasi Hasil Penilaian Kapasitas Wilayah Pesisir Pesisir Bagian Barat Kabupaten Buleleng

\begin{tabular}{llcc}
\hline No & \multicolumn{1}{c}{ Nama Desa } & Skor Kapasitas & Tingkat Kapasitas \\
\hline 1 & Kalisada & 38 & Sedang \\
2 & Br. Asem & 38 & Sedang \\
3 & Umaanyar & 35 & Sedang \\
4 & Kalapaksa & 35 & Sedang \\
5 & Pengastulan & 37 & Sedang \\
6 & Seririt & 38 & Sedang \\
7 & Sulanyah & 37 & Sedang \\
8 & Tangguwisia & 38 & Sedang \\
9 & Kalianget & 35 & Sedang \\
10 & Sumber Klampok & 40 & Sedang \\
11 & Pejarakan & 38 & Sedang \\
12 & Sumberkima & 38 & Sedang \\
13 & Pemuteran & 38 & Sedang \\
14 & Banyupoh & 37 & Sedang \\
15 & Penyabangan & 39 & Sedang \\
16 & Musi & 37 & Sedang \\
17 & Sanggalangit & 37 & Sedang \\
18 & Gerokgak & 37 & Sedang \\
19 & Patas & 38 & Sedang \\
20 & Pengulon & 39 & Sedang \\
21 & Celukan Bawang & 37 & Sedang \\
\hline
\end{tabular}

Sumber : Analisis Data Penelitian (2017)

Merujuk pada Tabel 1, diperoleh tingkat kapasitas wilayah penelitian adalah sedang. Agar lebih representatif mengenai sebaran tingkat kapasitas wilayah penelitian, skor tingkat kapasitas wilayah kemudian diolah dengan software ArcGis untuk memperoleh peta sebaran tingkat kapasitas di lokasi penelitian. Berdasarkan proses yang sudah dilakukan, maka diperoleh peta sebaran tingkat kapasitas wilayah penelitian sebagaimana disajikan pada Gambar 3

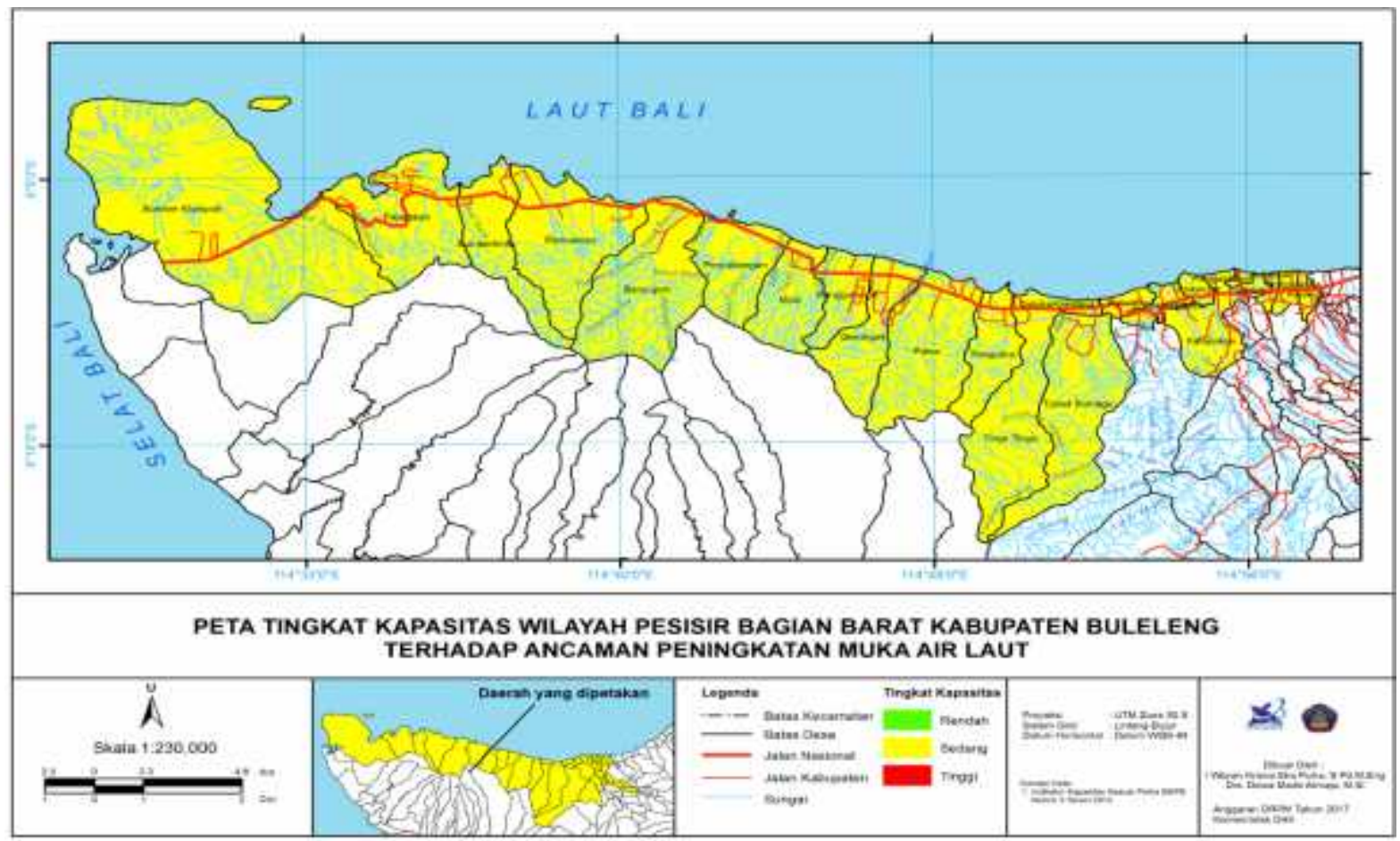

Gambar 3. Kapasitas Wilayah Pesisir Bagian Barat Kabupaten Buleleng 
Memperhatikan Gambar 3, diketahui sebaran tingkat kapasitas wilayah pesisir bagian barat Kabupaten Buleleng berada pada kategori sedang. Walaupun hasil perbandingan tingkat kapasitas wilayah penelitian menunjukkan semua desa berada pada kategori sedang, namun terdapat perbedaan skor total tingkat kapasitas masing-masing desa. Desa yang memiliki skor kapasitas paling tinggi
(40) adalah Desa Sumber Klampok, sementara desa yang memiliki skor kapasitas paling rendah (35) adalah Desa Umaanyar, Kalapaksa, dan Kalianget. Hasil analisis menunjukkan bahwa indikator yang dominan menyebabkan adanya perbedaan skor total kapasitas adalah pada indikator ketersediaan peta ancaman bencana dan sistem peringatan dini seperti divisualisasikan pada Tabel 2.

Tabel 2. Indikator Kapasitas

\begin{tabular}{|c|c|c|c|c|}
\hline \multirow[t]{2}{*}{ No } & \multirow[t]{2}{*}{ Nama Desa } & \multicolumn{3}{|c|}{ Nilai Per Indikator Kapasitas } \\
\hline & & Peta Ancaman & $\begin{array}{c}\text { Sistem Peringatan } \\
\text { Dini }\end{array}$ & $\begin{array}{c}\text { Sistem Kerja } \\
\text { Peringatan Dini }\end{array}$ \\
\hline 1 & Kalisada & 1 & 1 & 1 \\
\hline 2 & Br. Asem & 1 & 1 & 1 \\
\hline 3 & Umaanyar & 0 & 0 & 0 \\
\hline 4 & Kalapaksa & 0 & 0 & 0 \\
\hline 5 & Pengastulan & 0 & 1 & 1 \\
\hline 6 & Seririt & 1 & 1 & 1 \\
\hline 7 & Sulanyah & 0 & 1 & 1 \\
\hline 8 & Tangguwisia & 1 & 1 & 1 \\
\hline 9 & Kalianget & 0 & 0 & 0 \\
\hline 10 & Sumber Klampok & 1 & 1 & 1 \\
\hline 11 & Pejarakan & 1 & 0 & 0 \\
\hline 12 & Sumberkima & 1 & 0 & 0 \\
\hline 13 & Pemuteran & 1 & 0 & 0 \\
\hline 14 & Banyupoh & 0 & 0 & 0 \\
\hline 15 & Penyabangan & 0 & 1 & 1 \\
\hline 16 & Musi & 0 & 0 & 0 \\
\hline 17 & Sanggalangit & 0 & 0 & 0 \\
\hline 18 & Gerokgak & 0 & 0 & 0 \\
\hline 19 & Patas & 1 & 0 & 0 \\
\hline 20 & Pengulon & 0 & 1 & 1 \\
\hline 21 & Celukan Bawang & 0 & 0 & 0 \\
\hline
\end{tabular}

Sumber : Analisis Data Penelitian (2017)

Berdasarkan Tabel 2, hasil penelitian menunjukkan tidak semua desa memiliki peta ancaman bencana serta sistem peringatan dini. Hal tersebut terlihat pada Tabel 2, sebagian desa (dengan nilai 0 ) belum memiliki peta ancaman maupun sistem peringatan dini. Masih belum seragamnya ketersediaan peta ancaman bencana di masing-masing desa menunjukkan belum maksimalnya pemanfaatan dokumen kajian bencana yang sudah dibuat oleh BPBD Kabupaten
Buleleng. Lebih lanjut, setelah dikonfirmasi kepada BPDB Kabupaten Buleleng, menjelaskan bahwa pihaknya saat ini sudah memiliki dokumen peta ancaman bencana yang terdiri dari Peta Ancaman Bencana Tanah Longsor, Banjir, dan Banjir Bandang (BPBD, 2017). Dokumen kajian bencana tersebut merupakan hasil penelitian yang dilakukan oleh BPBD Kabupaten Buleleng bekerjasama dengan pihak konsultan untuk melakukan pendataan daerah 
potensi bencana di Kabupaten Buleleng. Sebagai tindaklanjut hasil dokumen tersebut, desa yang belum memiliki peta ancaman bencana dapat langsung meminta kepada BPBD Kabupaten Buleleng. Sementara untuk sistem peringatan dini memang saat ini masih menjadi kendala karena keterbatasan dana. Peran pemerintah dalam hal ini BPBD sangat diharapkan oleh pemerintah desa, mengingat berdasarkan informasi dari aparat desa tidak ada alokasi anggaran dana desa untuk penyediaan peta ancaman bencana begitu juga sistem peringatan dini. Padahal sesungguhnya peta ancaman bencana maupun sistem peringatan dini sangat dibutuhkan oleh pihak desa agar bisa melakukan upaya mitigasi bencana.

\section{Kesimpulan}

Berdasarkan hasil analisis data, diperoleh bahwa semua desa yang berada di wilayah pesisir bagian barat Kabupaten Buleleng memiliki tingkat kapasitas kategori sedang. Kondisi tersebut menunjukkan bahwa pemerintah sudah melakukan upaya mitigasi bencana. Namun demikian, masih ditemukan adanya ketimpangan indikator kapasitas pada beberapa desa terutama mengenai ketersediaan peta ancaman dan sistem peringatan dini. Kondisi tersebut menuntut perlu dilakukan sosialisasi terhadap dokumen kajian bencana yang sudah dibuat oleh BPBD Kabupaten Buleleng.

\section{Ucapan Terima Kasih}

Terimakasih diucapkan kepada LPPM Undiksha atas dana penelitian yang diberikan. Informan yang dalam hal ini aparat desa dan BPBD Kabupaten Buleleng atas informasi yang diberikan, serta mahasiswa Jurusan D3 Survei dan Pemetaan yang telah membantu dalam proses pengumpulan data.

\section{Daftar Pustaka}

BNPB, 2008, Pedoman Penyusunan Rencana Penanggulangan Bencana. Peraturan Kepala Badan Nasional Penanggulangan Bencana No. 4 Tahun 2008.

BPBD Kabupaten Buleleng. 2017. Laporan Kegiatan Pendataan Daerah Potensi Rawan Bencana di Kabupaten Buleleng.

Butaru. 2011. Kewajiban Kita Dibalik Keindahan Wilayah Pesisir Bali. Badan Koordinasi Penataan Ruang Nasional.

Damayanti, H.O. 2012. Ketinggian Muka Air Laut Rata-rata (MSL) di Perairan Kabupaten Pati. Tersedia pada http://litbang.patikab.go.id. diakses pada Senin, 15 Juli 2013.

Nugraha, A. L. 2013. Penyusunan dan Penyajian Peta Online Risiko Banjir Rob Kota Semarang. Tesis. Yogyakarta : Program Studi Teknik Geomatika, Universitas Gadjah Mada.

Putra, I Wayan Krisna Eka. 2013. Evaluasi Hasil Post-Processing Data Satelit Altimetri Envisat Sebagai Data Prediksi Ancaman Peningkatan Muka Air Laut Untuk Pemetaan Genangan Wilayah Pesisir (Studi Kasus Wilayah Pesisir Kabupaten Buleleng Bagian Barat). Tesis. Yogyakarta : Program Studi Teknik Geomatika, Universitas Gadjah Mada.

Sihombing, W.H., Suntoyo, dan Kriyo S. 2012. Kajian Kenaikan Muka Air Laut di Kawasan Pesisir Kabupaten Tuban, Jawa Timur. Jurnal Teknik ITS, Vol. 1, ISSN: 2301-9271.

Wirasatriya, A. 2005. Kajian Kenaikan Muka Laut Sebagai Landasan Penanggulangan Rob di Pesisir Kota Semarang. Tesis. Program Studi Magister Manajemen Sumber Daya Air. Pascasarjana UNDIP. Semarang. 